\title{
Liquido cefalorraquídeo inicial normal y Meningitis bacteriana aguda
}

\author{
Dres.: José Baeza,* Antonio Banf;** y José Zacarias**
}

\begin{abstract}
The need for repeated diagnostic lumbar punctures in sone cases of acute bacterial meningitis with absent or minintal cerebrospinal fluid abnomalities is emphazlsed based on the experience with five patients with normal initial cerebro-spinal Huirs.

A review of the literature and a discussion about the possible role of lumbas puncture in the causition of meningitis are presented.
\end{abstract}

La punción lumbar (PL) corıstituye el procedimiento más válioso para establecer el diagnóstico de meningitis bacteriana aguda. Lo infrecuente de sus complicaciones y las ventajas que proporciona sll ejectción, al permitir un precoz reconocimiento de esta patologia, determinan que sea realizada sin vacilación ante una mímirna sospeclat.

Si en el análisis posterior, el líquido cefalorraquideo (LCR) es normal, generalmente el diag-

\footnotetext{
- Trabajo de incrorporación a la Soxiedad Chilena de Pediatria
} ** Servicio de Pediatria, Hospital "Luis Calvo Mackenna". nóstico de meningitis purulenta es definitivamente descartado y una segunda PL es considerada innecesaria.

En los últimos cuatro anos hemos observado en el Hospital Luis Calvo Mackenna, cinco pacientes, en los cuales una segunda PL realizada pocas horas después que una inicial mostrara un LCR nommal, reveló la presencia de meningitis purulenty.

Nos ha parecido de interés comunicar las características clínicas de estos pacientes y señalar en qué condiciones un examen repetido del LCH debe ser considerado en el diagnóstico injcial de meningitis bacteriana agudi. 


\section{CASOS CLIYICOS}

Caso 1 M.G.G. (Obs.: 356152) Lactante de un mes de edad que inició su enfermedad cinco días antes de su ingreso con quejido y rechazo alimentario. Al segundo día de esta síntomatología concurrió al Servicio de Urgencia; ante la sospecha de meningitis se practicó PL cuyo examen ciloquiin ico era nomal. Enviado a su casa persistió con la sintomatologia descrita y además vómitos repetidos. Consultó nuevamente al día siguiente, se verificó que el resultado del estudio bacteriológico del LCR era negativo y fue enviado a su domi- cilio cun indicaciones dietéticas. En las siguientes 48 horas evolucionó con progresivo comproniso de su estado general y de conciencia y momentos antes de su tercera consulta y hospitalización, su respiración se hizo irregular ingresando con paro respiratorio. Conectado a ventilador mecánico, se practicó una mueva PL extrayéndose un lípuido purrlento con marcadas alteraciones al examen citoquímico (Tabla 1). El gram mostraba aldundarstes diplococos positivos que se identificarori en el cultivo como Streptococcus pneunoniae. El paciente falleció a las seis horas de ingresado.

Tabla 1

Resultados de los eximenes citomuinuico y facteriológico del LC:F en cinco pacientes con meningits batcteriana agilda

\begin{tabular}{|c|c|c|c|c|c|}
\hline Citso & l & 2 & 3 & 4 & 5 \\
\hline obs. & $3561 \div 2$ & $36567 i$ & $2865 \times 4$ & 3020144 & 35,34111 \\
\hline Edal & 1 mes & $i$ meses & 3 meses & 3 añ & 12 años \\
\hline \multicolumn{6}{|l|}{ LCR. Inicial } \\
\hline Lencoxitosimno & 0 & $\mathbf{3}$ & 了 & ca & 10 \\
\hline Gliacosa mag. $\%$ & (x) & 54 & 59 & 75 & 72 \\
\hline Albimina sug. \% & 3) & 70 & 25 & 13 & 12 \\
\hline Pandy & - & $\ldots$ & - & - & - \\
\hline Gram & -- & $\cdot$ & - & - & + \\
\hline Cultivo & - & - & E. Coli & N. metringitic & N. meningitidis $C$. \\
\hline \multicolumn{6}{|l|}{ Intervalo entre } \\
\hline \multicolumn{6}{|l|}{$2 L C R$} \\
\hline \multirow[t]{2}{*}{ Leucositos/mu⿰氵 } & 50 & 4.350 & $19.6(x)$ & 12.500 & sors \\
\hline & $46 \% \mathrm{PN}$ & $80 \% \mathrm{PN}$ & $93 \%$ PN & $85 \% \mathrm{PA}$ & $90 \% \mathrm{PN}$ \\
\hline G]ucosa mg. \% & 0 & 0 & 47 & 25 & 11 \\
\hline Albúminat mg. & 450 & 100 & 20 & 150 & 440 \\
\hline Pandy & +++ & +++ & +++ & +++ & \\
\hline Gram & + & + & + & -. & \\
\hline \multirow[t]{2}{*}{ Cintive } & St. pueumoniate & Hlatemephilus & E. colli & - & + \\
\hline & & & & & $\mathrm{N}$ meningtitidis $\mathrm{C}$ \\
\hline
\end{tabular}

Caso 2 A.C.C. (Obs.: 365677 ) Lactante de 7 meses ane fue ingresado por presentar mo flegmón facial de dos dias de evolución parcialmente tratado con Ampicilina oral. A su admisión se encontraba febril y quejumbroso. Su primera PL mostró un LCR claro y sin anonnalidades at examen cikoguímico y bacteriologico (Tabla i). Por las caracteristicas clínicas ded flegnon se sospertór qute ficera originado por $\mathrm{H}$ atemophilus $y$ se indicró tratamiento con anpicilina EV. En las horas siguien- tes las condiciones generales del paciente desmejoraron, evidenciándose aparición de compromiso de consiencia, polipnea superficial $y$ mayor extensión de la lesión tacial. $A$ las $\mathbf{4 8}$ horas de hospitalizado el comproniso de conciencia se habia profundizado, siendo notorio un abombamiento del bregna y crisis de higertonía. Una seggmelia PI, revelo un líquido paralento del ane se aisló Hatemophilus sp. Su evolución posteriar mostró iII progresivo enıpeoramiento no lográmdose 
erradicar el germen del LCR a pesar de los sucesivos esquemas terapéuticos empleados, falleciendo al noveno dia de ingresado.

Caso 3 G.S.R. (Obs.: 286584) Lactante de 3 meses hospitalizado por un cuadro de diarrea con deshidratación. En su examen de admisión se comprobó ademas, una otitis media aguda. Se realizó paracentesis timpánica y se indicó hidratación parenteral y penicilina sódica IM. A segundo día de ingresado continuaba febril, destacando la presencia de irritabilidad marcada y compromiso general. Un examen del LCA no mostró anormalidades en el análisis citocjuímico ni en la tinción del gram. Se mantuvo el mismo esquema de tratamiento no observándose mejora del enfermo que persistía febril e irritable. En el cultivo del LCR, después de 23 horas de incubación se informo desarrollo de bacterias gram negativas, ante estos hechos se repitió la PL que reveló ahora un lícuuido turbio (Tabla 1). El estudio bacteriológico del cultivo de ambas muestras identificó al gérmen como $\mathbf{E}$. coli. El paciente recibió tratamiento con gentamicina y ampicilina durante 12 días, lográndose rápida esterilización del LCR.

Caso 4 B.R.L. (Obs.: 302084) Preescolar de 3 años que consultó por presentar desde 11 horas antes de su ingreso cuadro febril y aparición de lesiones periorbitarias. Al examen de ingreso se comprobó la presencia de lesiones petequiales y equimóticas diseminadas y signos meníngeos esbozados. Su LCR. inicial no mostraba alteraciones (Tabla 1). Por el cuadro clínico sugerente de meningococcemia se instauró tratamiento con penicilina sódica $\mathrm{EV}$; su evolución en las $\mathbf{1 2}$ horas siguientes reveló progresivo compromiso de conciencia, mayor extensión de las lesiones cutáneas $y$ sus signos meníngeos se intensificaron. Una nueva PL mostró en esta ocasión un líquido con marcadas alteraciones al examen. El cultivo de la primera muestra de LCR revelo desarrollo de Neisseria meningitidis grupo C. La tinción de gram y cultivo del segundo líquido fueron negativos. El paciente evolucionó sin complicaciones y fue dado de alta sin secuelas detectables.

Caso 5 L.P.A. (Obs.: 353401 ) Escolar de 12 años que ingresó por cefalea, fiebrè, vómitos y decaimiento iniciado 24 horas antes. En su evaluación inicial se encontraba consciente, febril y en su brazo izquierdo tenía dos pequeñas lesiones pete- quiales. El examen neurológico mostraba signos meníngeos esbozados. En su primera PL se obtuvo un líquido sin anormalidades al examen citoquímico y no se observaron gérmenes en el gram inicial (Tabla 1). Se hospitalizó para observar con el diagnóstico ínicial de estado infeccioso. Examinado 8 horas más tarde se comprobó que las condiciones del paciente habían empeorado, sus lesiones petequiales se habían diseminado y extendido y los signos meníngeos se habían constituido claramente. La repetición de la PL reveló un líquido punuento. En los cultivos de ambas muestras se aisló Neisseria meningitidis grupo $C$. El paciente recibió tratamiento con penicilina sódica y no presentó complicłaciones.

\section{COMENTARIO}

Al analizar nuestros casos nos encontramos frente a dos situaciones distintas.

En los dos primeros pacientes el LCR inicial no mostraba anormalidades en el examen citoquímico ni bacteriológico. A pesar de su evolución posterior, con progresivo compromiso general y de conciencia, la nonnalidad del mismo fue determinante para que el diagnóstico de nreningitis se reconsiderase śblo tardíamente, cuando los signos de hipertensión endocraneana y edema cerebral eran evidentes. El desenlace latal de ellos, estuvo en gran parte determinado por una innecesaria prolongación del período de observación, antes de decidir la realización de un nuevo examen del LCR.

El rápido desarrollo de meningitis después de una PL inicial nomal es infrecuente pero está claramente documentado en la literatura extranjera. 1, 2, 3, 4, 5 Algunos autores, considerando que la mayoría de los casos reportados comparten como elemento común la presencia de bacteremia cuando la primera PL fue realizada, han sugerido que este procedimiento pueda haber facilitado el desarrollo posterior de meningitis. ${ }^{12,4}$ La existencia de evidencias experimentales que demuestran esta situación en animales sometidos a bacteremia $^{6,7}$ ha contribuido a que esta teoria sea contemplada.

Afortunadamente esta asociación (bacteremiapunción lumbar-meningitis) que haria reconsiderar la inocuidad de la PL, no ha logrado serdemostrada en seres humanos ${ }^{5}$ y en los modelos experimentales los mecanismos postulados como causa- 
les no han sido confirmados y hasta el momento parecen ser ignorados.

Que un paciente desarrolle o no meningitis después de una PL, creemos que depende de factores más importantes que este procedimiento y que están vinculados con la naturaleza del huêsped, el número de microorganismos infectantes y su virulencia. ${ }^{8,9,10,11}$ Estos dos factores finales están claramente presentes en nuestros enfermos.

Los tres últimos pacientes difieren de los anteriores, en que en ellos se demostró crecimiento de gérmenes en los cultivos del primer LCR, por tanto, la infección meníngea estaba presente a su ingreso. En los pacientes 4 y 5 , la intensificación de los signos meníngeos presentes ya en su admisión, la evolución posterior que demostró progresivo compromiso de conciencia y la experiencia obtenida con los casos anteriores, detenninó la repetición precoz de la PL, aun antes de que hubiese sido informado crecimiento bacteriano en los cultivos.

Si comparamoss la historia de ellos, con la de los pocos casos publicados en la literatura ${ }^{12,13,14}$ vemos que el elemento común es la corta evolución de su enfermedad al momento de realizar la PL inicial. La falta de evidencias de inflamación en el análisis químico y resuento celular del LCR, es probable que sea condicionado porque la infección meningea hubiese ocurrido recientemente $y$ la respuesta inflamatoria característica del huésped no se hubiera aún desarrollado o manifestado a nivel del líquido espinal.

Más importantes que tratar de comprender los mecanismos implicados en el desarrollo de meningitis en nuestros casos, nos parecen las conchsiones que deben obtenerse del análisis de la evolución de estos pacientes y de los notificados en la literatura. De ellas surgirán conductas terodientes a facilitar el diagnóstico precoz de meningitis, cuando se presenten situaciones como las relatadas.

En este sentido es necesurio señalar, que la renuencia de algunos médicos para realizar un segundo examen del LCR basandose en la normalidad de uno reciente y/o en la remota y no comprobadia posibilidad (pue este procedimiento pueda facilitar el desarrollo de merningitis, no es justificable.

La presencia de un examen de LCR normal en il) paciente con un cuadro clínico sugerente de meningitis no descarta en algunas ocasiones este diagnóstico, siendo conveniente mantener al pa- ciente en observación por un período prudente, especialmente si tiene una historia corta de enfermedad.

Si durante dicha observación, la sintomatología persiste o se intensifica, una segunda punción lumbar debe ser realizada.

La experiencia mostrada en este trabajo, así como la obtenida de la revisión de las publicaciones extranjeras citadas, avalan plenamente eşta conducta.

\section{RESUMEN}

Se presentan cinco pacientes, en cquienes el diagnóstico de meningitis pundenta dependió de la realización de una segunda punción lumbar, pocas horas después que un examen inicial de LCR no mostrara signos de infección al análisis químico, recuento celular y tinción de gram.

Se revisan las publicaciones de casos semejantes en la literatura y se comentan las posibles explicaciones de la nomnalidad de este examen en la primera punción lumbar.

Se analiza la evolución de los pacientes y se concluye que en algunas situaciones un examen repetido del $L C R$ puede ser necesario para establecer el diagnóstico de meningitis bacteriana aguda.

\section{REFERENCIAS}

${ }^{l}$ Rapkin, R. H. Repeut lumbar punctures in the diagnosis of meningitis. Pediatries. 54 : 3437, 1974.

2 Fischer, G. M. Brenz, R. W. Alden. E. A.: Beciwith. J. B. Lumbar puncture and tneningitis. An. J. Wis. Child. 129: 500-593, 1975.

${ }^{3}$ Wegeforth. P., Latham, J. R. Lumbar puncture as a factor in the vausation of meningitis. Art. J. S.i. 148: 183-202, 1919.

4 Remson, $D . B$. The role of lumbar puncture in the causation of meningitis. J. Med. 17: 115-1936.

5 Pray L. G. Lumbar puncture as a tactor in the pathogeriesis of meningitis. Ans. J. Dis. Chil. 62; 295-308, 1941.

6 Petersdorf, R. G.: Swarner. D R.; Garcic, $M$ Studjes on the pathogenesis of meningitis: II. Develoment of meningitis during pneumococeal bacteremia. J. Clin. Invest. 41: 320327,1962 .

7 Weed. L. H.; Wegeforth. P.: Ayer, S. B. ef ut. The prodiction of meningitis by release of cerebrospmal fluid during an experimental septicemia. Prelimintary note. J.A.M.A. 72: 190 $193,1919$.

8 Pesersdoff, R, G.: Iustrell, C. N. Studies on the palugenesis of meningitis: Intrathecal intection. J. Chn. lovest 41:31 1-319 1962.

SMc. Gowerr, J. E.; Klein, J.O.; Bronon. L. et al. Meningitis and bacteremia due ts Haemphilus influenzae: Occurrence and mortality at Buston City Hospital in 12 selacted years, 19351972. J. Intect. Dis. 130: 119-12A, 1974.

10 Mc Cracken, G. H. Sarr. L. D; Ginde, M. al ablationsh!p betweer Escherichua coli $\mathrm{K}$, capsula polysacchuride antigen and clinical outcone in neunatul meningitis. Iancel 2; 24625(1), 1974 . 
11 Feigin, R. O.; Dadge, P. R. Bacterial meningitis. Newer concepts of pathophysiology and neurologic sequelae. Pediat. Clin. North Ain. 23: 541-556, 1976.

12 Moore, C. M.; Ross. M. Acute bacterial meningitis with absett or minimal cerebrospinal Iluid abnormalities. Clin. Pediatr. 12: 117-118, 1973 .
13 Swartz. M. N.; Dodge, P, R. Bacterial meningitis -a review of selected aspects. V. Engl. J. Med. 272: 725-731, 1965.

14 Visser. V. E.; Hall, R. T. Lumbar puncture in the evaluation of suspected neonatal sepsis. J. Pediat. 96: 1063-1067, 1980. 